\title{
Viabilidade da Utilização de Argamassa Estabilizada Através do Ensaio de Arrancamento
}

\author{
Viability of the Use of Stabilized Mortar through the Pullout Test
}

\begin{abstract}
Rafael Araújo Dias Silva1 (Dorcid.org/0000-0001-5271-1240
RodolfoBringel Pereira1 ${ }^{1}$ orcid.org/0000-0002-9050-8566
\end{abstract}

\author{
YêdaVieira Póvoas² (Borcid.org/0000-0003-1907-415X \\ ${ }^{1}$ Escola Politécnica de Pernambuco, Universidade de Pernambuco, Recife, Brasil, \\ 2 Programa de Pós-graduação em Engenharia Civil, Escola Politécnica de Pernambuco, Brasil. \\ E-mail do autor principal: Rafael Araújo rafael.araujods@live.com
}

\section{RESUMO}

Com o passar dos anos, a indústria da construção civil busca métodos de otimizar os serviços através de novas técnicas e novos materiais. A argamassa estabilizada se tornou uma ótima opção para ganhos de prazo, custo e produtividade. Porém, a falta de normas específicas e pouco conhecimento do material faz com que o produto final tenha resultados irregulares na sua fabricação. Este trabalho tem por objetivo mostrar a viabilidade técnica do uso de argamassas estabilizadas para revestimentos externos, analisando sua capacidade de aderência através do ensaio de resistência de aderência à tração e comparando com os resultados exigidos pelas normas vigentes. Foi verificada a aderênciada argamassa de emboço em uma obra localizada em Recife/PE em duas situações distintas: ambiente externo com e sem limpeza da base. Ao fim do ensaio comprovou-se a qualidade do produto final do revestimento realizado conforme a ABNT NBR 7200:1998, com a realização do tratamento de limpeza, pois todos os valores obtidos deste trecho foram aprovados e satisfatórios, entretanto não foi detectado o incremento de tensão proveniente desse tratamento.

PALAVRAS-CHAVE: Argamassa estabilizada; Argamassa de revestimento; Revestimento de fachada; Resistência de aderência.

\section{ABSTRACT}

Over the years, the construction industry has been looking for ways to optimize services through new techniques. Stabilized mortar has become a great choice for time, cost and productivity gains. However, the lack of specific standards and little knowledge of the material causes the final product to have irregular results in its manufacture. This work aims to show the technical feasibility of the use of stabilized mortars for external coatings, analyzing their adhesion ability through the tensile strength test and comparing with the results required by current standards. An adhesion test was carried out on the plaster mortar in a construction site located in Recife / PE in two different situations: external environment with and without cleaning of the base. At the end of the test, the final product of the coating performed according to NBR 7200:1998, with the cleaning treatment, was verified since all values obtained from this section were approved and satisfactory, however, the increase in tension from the treatment was not detected.

KEY-WORDS: Stabilized mortar; Coating mortar; Façade coating; Tensile strength. 


\section{INTRODUÇÃO}

O setor da construção civil está em constante melhoria dos serviços e otimização dos processos, sempre buscando a diminuição dos custos globais. Essas necessidades impulsionaram 0 desenvolvimento de estudos e pesquisas a fim de criar novos produtos e procedimentos para substituir ou ampliar as opções a serem empregadas em cada situação.

Um dos produtos mais utilizados na construção civil é a argamassa, tendo as mais distintas finalidades. Dentre elas, está inserida a função de revestimento.

A industrialização das argamassas teve início nos anos 50, porém apenas na década de 70 , na Alemanha, foram desenvolvidos aditivos que garantiram as características de uso por três dias. No Brasil, o primeiro registro de uso da argamassa estabilizada é datado de 1985 [1].

A argamassa estabilizada surge como uma opção versátil, produtiva e econômica. A limpeza e a redução do tempo no cronograma são características que tornam cada vez mais atrativa a sua utilização. Além disso, uma das prerrogativas na decisão de optar por um produto industrializado como esse é o seu recebimento em condições de aplicação, otimizando o tempo do responsável técnico [2].

A pouca literatura existente sobre argamassa estabilizada é um dos fatores predominantes pelo baixo conhecimento e pela baixa procura por parte das construtoras. As normas específicas vigentes são quase inexistentes sobre o tema.

O presente trabalho tem função de ampliar os conceitos e divulgação no que concerne à argamassa estabilizada, avaliando a viabilidade da utilização da mesma por meio do ensaio de resistência de aderência à tração, analisando a contribuição da limpeza do substrato e do chapisco nos resultados.

\section{CAMADAS DO REVESTIMENTO}

Os revestimentos de argamassa têm como função proteger os elementos de vedação das edificações da ação direta dos agentes agressivos, auxiliar as vedações no cumprimento das suas funções, regularizar a superfície dos elementos de vedação, servir de base para aplicação de outros revestimentos ou constituir-se no acabamento final [3].
As camadas que compõem o revestimento de argamassa são definidas e caracterizadas pelo Manual da Argamassa de Revestimento [4], conforme a Figura 1.

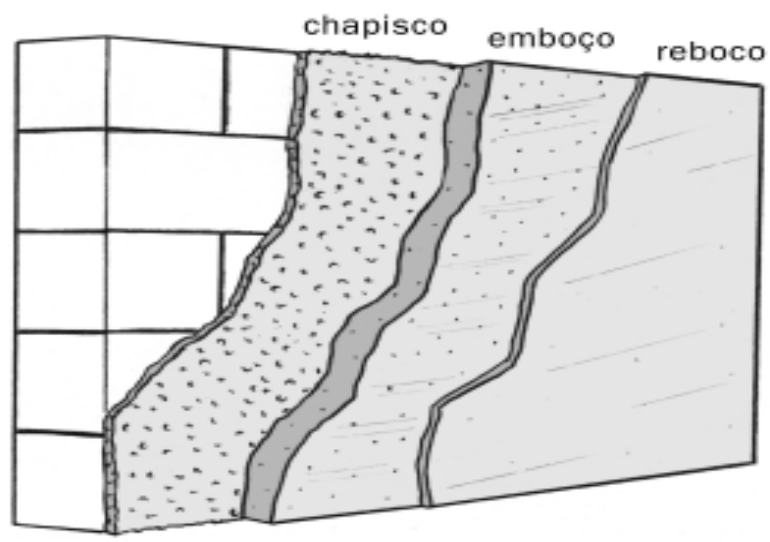

Figura 1: Camadas do revestimento. Fonte: $A B C P$ [s.d.]

- Substrato: é a base para aplicação das camadas de revestimento, normalmente os mais empregados são as bases de alvenaria e estrutura de concreto [3].

- Chapisco: camada de preparo da base, constituída de mistura de cimento, areia e aditivos, aplicada de forma contínua ou descontínua, com a finalidade de uniformizar a superfície quanto à absorção e melhorar a aderência do revestimento.

- Emboço: camada de revestimento executada para cobrir e regularizar a superfície da base com ou sem chapisco, propiciando uma superfície que permita receber outra camada de reboco ou de revestimento decorativo, ou que se constitua no acabamento final.

- Reboco: camada de revestimento utilizada para o cobrimento do emboço, propiciando uma superfície que permita receber o revestimento decorativo ou que se constitua no acabamento final.

- Massa Única (emboço paulista): revestimento executado em uma camada única, cumprindo as funções do emboço e reboco.

\section{ARGAMASSAS DE REVESTIMENTO}

Argamassa é a mistura de aglomerantes, agregados e água, possuindo capacidade de endurecimento e aderência [5]. 
As argamassas empregadas em revestimentos devem conter materiais e suas respectivas proporções de dosagem compatíveis com o acabamento e condições de exposição previstas; ter resistência mecânica compatível como o acabamento decorativo selecionado; e quando coloridas, o pigmento deve resistir à ação da radiação ultravioleta e à alcalinidade das argamassas [6].

Em geral, o traço para argamassa de revestimento é composto por areia fina e média, cimento, cal e aditivos.

As argamassas estabilizadas são aquelas que chegam à obra prontas para uso e possuem a capacidade de se manter trabalháveis por longos períodos de tempo[7]. Uma vez aplicada, seu comportamento é semelhante ao das argamassas convencionais. Essas argamassas são produzidas em centrais dosadoras, passando por um processo criterioso de produção.

As argamassas estabilizadas possuem vantagens em comparação às argamassas tradicionalmente produzidas em canteiros [8]:

- aumentodo rendimento: evita paradas para aguardar a confecção da argamassa, além do período no início do expediente;

- redução de perdas: a argamassa não precisa ser utilizada toda em um dia, evitando que, ao final da jornada de trabalho, a sobra seja descartada;

- limpeza da obra: reduz os resíduos provenientes da confecção de argamassas em obra (embalagens de cimento, cal e aditivos, por exemplo);

- misturas mais consistentes: devido ao fato da proporcionalidade dos materiais ser feita em central, em massa, com maior controle;

- reduz a responsabilidade de dosagem em obra;

- melhora a logística dentro do canteiro de obra: os recipientes contendo a argamassa podem ser descarregados próximos aos locais de utilização, reduzindo o transporte dentro da obra;

- reduz a demanda de mão de obra, uma vezque dispensa o processo de mistura e reduz o transporte dentro do canteiro de obras.

\section{MATERIAIS E MÉTODOS}

A presente pesquisa foi desenvolvida através de ensaio de resistência de aderência à tração, seguindo recomendações da NBR 13528 [9], em obra localizada na cidade de Recife/PE.

Todo procedimento de execução do revestimento com argamassa estabilizada seguiu as especificações da NBR 7200 [5].

Para a realização do ensaio, foi selecionada uma área em ambiente externo contendo $3 \mathrm{~m}$ de comprimento por $2,45 \mathrm{~m}$ de altura, com elevação em alvenaria de blocos cerâmicos da família $(9 \times 19 \times 19) \mathrm{cm}$ com idade mínima de 14 dias, conforme Figura 2.

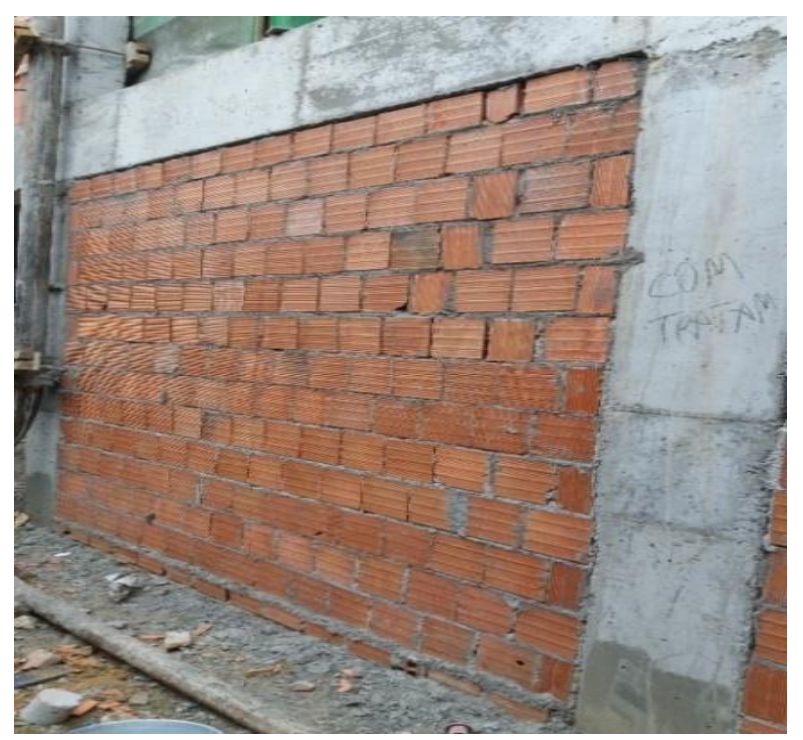

Figura 2: Elevação daalvenaria.

Fonte: Autor.

Inicialmente foi realizado o procedimento de limpeza e aplicação do chapisco. A área ensaiada foi dividida em dois trechos. Em um deles foi feita uma limpeza da base antes da aplicação do chapisco, com auxílio de broxa e água limpa, para remoção da poeira e materiais soltos (Figura 3 ). No segundo trecho, o chapisco foi aplicado diretamente, sem o processo de limpeza. 


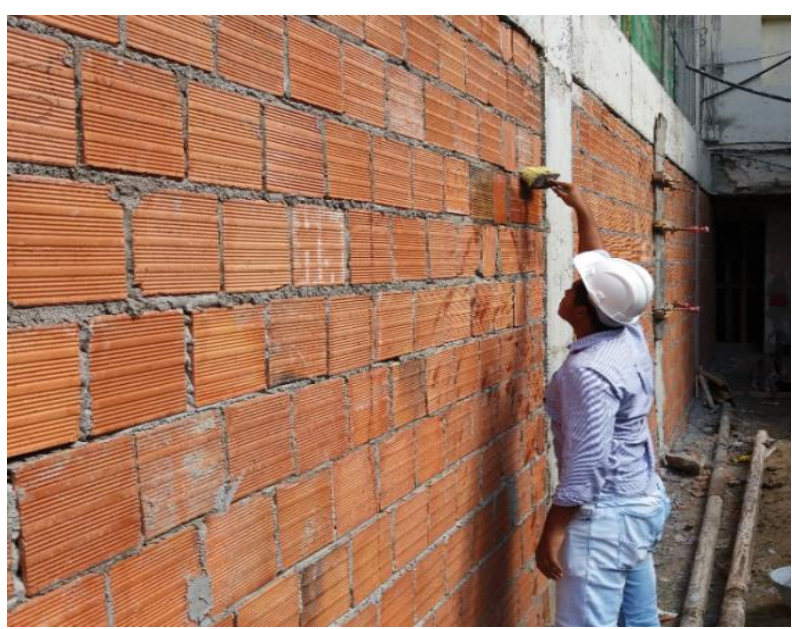

Figura 3: Limpeza da base.

Fonte: Autor.

O chapisco foi aplicado por apenas um funcionário e foi dosadona própria obra, com a proporção de 1:3 (cimento:areia). A Figura 4 mostra a alvenaria chapiscada.

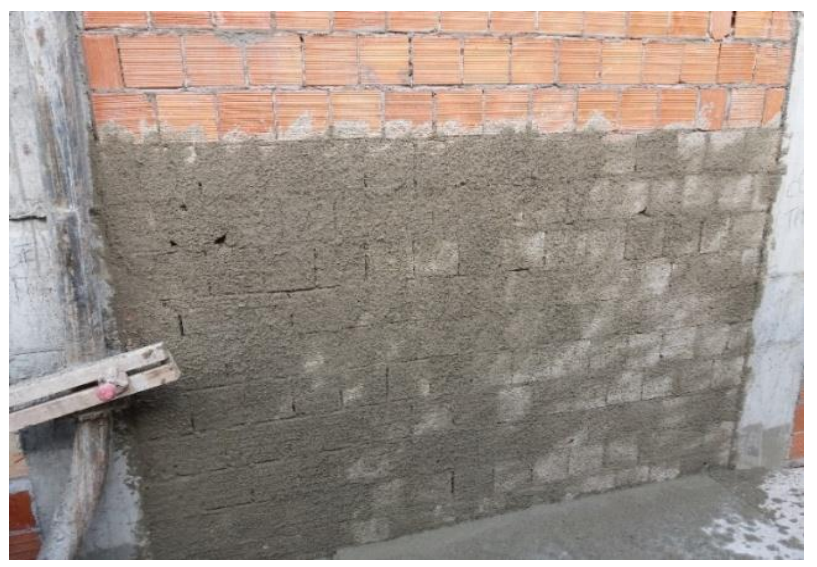

Figura 4: Alvenaria chapiscada.

Fonte: Autor.

Após 3 dias da aplicação do chapisco, foi realizada a aplicação do emboço utilizando argamassa estabilizada.

No mesmotrechoonde foi realizada a limpeza da base, fez-se uma nova limpeza, desta vez no chapisco, com o intuito de remover a poeira e os materiais soltos. O segundotrecho seguiu sem receber a execução da limpeza superficial.

Toda a aplicação foi realizada imediatamente após o recebimento da argamassa na obra, sendo aplicada pelo mesmo funcionário, através de projeção manual.o emboço foi aplicado em única camada, de aproximadamente $2 \mathrm{~cm}$ de espessura. A figura 5 mostra o resultado após a aplicação do emboço.
O tempo de pega da argamassa estabilizada utilizada foi de 36horas, porém o traço não foi disponibilizado pelo fabricante local, sendo apenas informado o aditivo estabilizador de viscosidade Eco-Tec Mix.

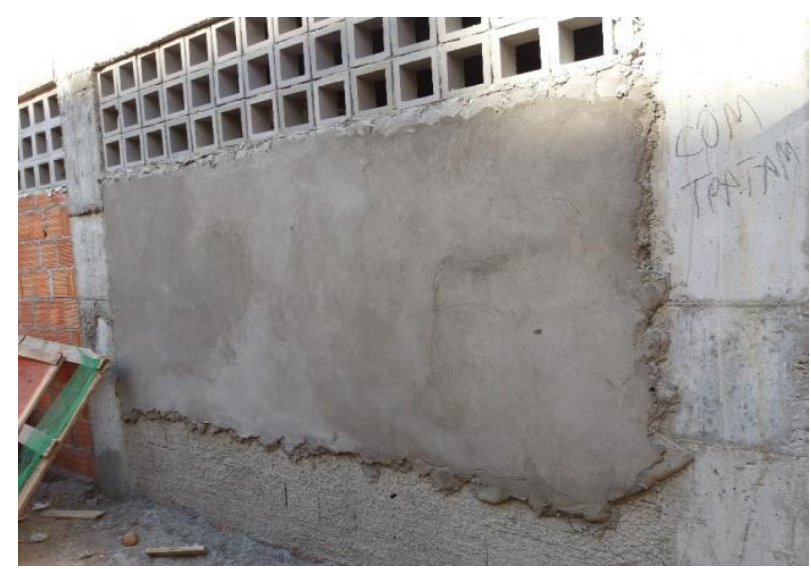

Figura 5: Emboço aplicado. Fonte: Autor.

Decorridos 27 dias da aplicação do emboço, foram selecionados 24 pontos para representação dos corpos de prova (CP's) para cada situação, sendo 12 deles na área coma realização da limpeza da base e do chapisco, e os outros 12, na área sem o tratamento.

Os corpos de prova foram cortados a seco,em formato circular, tendo $50 \mathrm{~mm}$ de diâmetro cada um, com profundidade de 1 a $5 \mathrm{~mm}$ para dentro do substrato. A distância de $50 \mathrm{~mm}$ foi obedecida entre osCP's.

O equipamento utilizado para a realização dos cortes foi a furadeira de impacto Bosch GSB 13 RE $650 \mathrm{~W}$, acoplada a uma serra copo JRC de $50 \mathrm{~mm}$ de diâmetro interno.

Foram cortados 15 corposdeprova de cada situação, porém apenas 12 foram selecionados e ensaiados (Figura 6 - em azul). Os demais (Figura 6 - em vermelho) foram extraídos aleatoriamente e enviados para o fabricante.

Com os corposdeprova definidos, a superfície da argamassa foi limpa e aplicada cola à base de resina epóxi Sikadur 31, para fixação das pastilhas metálicas. 


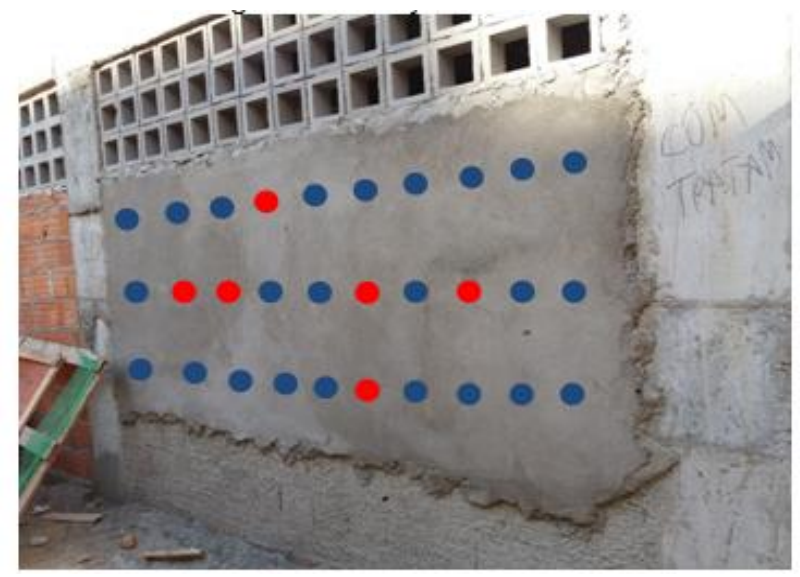

Figura 6:Locação dos cortes.

Fonte: Autor.

No dia seguinte à colagem das pastilhas, aos 28 dias da aplicação do emboço, foi realizado o ensaio de resistência de aderência à tração.Foi utilizado o aparelho de arrancamento hidráulico manual para argamassas, da marca Solotest, com indicação digital de força e memória de pico, capacidade de 1500 Kgf e resolução de 1 Kgf.

$\mathrm{O}$ aparelho foi encaixado por meio de um pino enroscado nas pastilhas e, com auxílio da manivela, foi exercida força de tração até o descolamento do testemunho, conforme Figura 7. A força utilizada para 0 arrancamento foi apresentada no indicador digital do equipamento e expressa em Kgf.

Os dados obtidos através do ensaio foram adicionados a uma tabela modelo que consta na normatização sobre revestimentos com argamassa inorgânica [9]. Estão contidos nesta tabela os valores das cargas, tensões e forma de ruptura dos corpos de prova ensaiados.

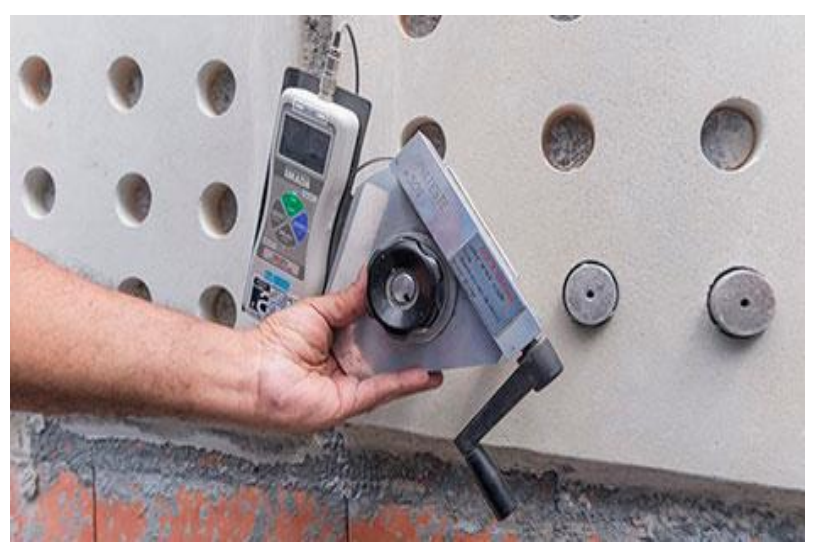

Figura7:Ensaio de resistência de aderência à tração. Fonte: mapa da obra.com.br.
Como resultado, dos 12 corpos de prova avaliados, 2/3 deles devem apresentar resultados iguais ou superiores a $0,30 \mathrm{MPa}$ para 0 revestimento ser aprovado, conforme especificação da NBR 13749 [6], indicada pelo Quadro 1, por se tratar de parede em local externo com acabamento em base para reboco (emboço).

Além disso,a forma de ruptura que não ocorrer na inte rface argamassa/substrato, substrato/chapisco e chapisco/argamassa indica que a resistência de aderência não foi determinada e é maior que o valor obtido no ensaio.

O cálculo da resistência de aderência à tração é realizado pela equação (1):

Onde:

$$
R a=\frac{P}{A}(\mathbf{1})
$$

$\mathrm{Ra}=$ resistência de aderência à tração, em MPa.

$\mathrm{P}=$ carga de ruptura, em $\mathrm{N}(1 \mathrm{Kgf}=9.8067 \mathrm{~N})$.

$\mathrm{A}=$ área da pastilha, em $\mathrm{mm}^{2}$.

Quadro1: Limites de resistência à tração (Ra).

\begin{tabular}{|c|c|c|}
\hline LOCAL & ACABAMENTO & $\mathbf{R a}(\mathbf{M P a})$ \\
\hline $\begin{array}{c}\text { PAREDE } \\
\text { INTERNA }\end{array}$ & $\begin{array}{c}\text { PINTURA OU BASE PARA } \\
\text { REBOCO }\end{array}$ & $\geq 0,20$ \\
\cline { 2 - 3 } & CERÂMICA OU LAMINADO & $\geq 0,30$ \\
\hline $\begin{array}{c}\text { PAREDE } \\
\text { EXTERNA }\end{array}$ & $\begin{array}{c}\text { PINTURA OU BASE PARA } \\
\text { REBOCO }\end{array}$ & $\geq 0,30$ \\
\cline { 2 - 3 } & CERÂMICA & $\geq 0,30$ \\
\hline TETO & - & $\geq 0,20$ \\
\hline $\begin{array}{c}\text { PISO } \\
\text { (INTERNO/ } \\
\text { EXTERNO) }\end{array}$ & CERÂMICA & $\geq 0,30$ \\
\hline
\end{tabular}

Fonte: NBR 13749 [6].

Não foi realizado o ensaio de determinação da umidade do revestimento.

\section{RESULTADOS}

\subsection{Ensaio sem tratamento do substrato e do chapisco}

A Tabela 1 expressa os valores obtidos do ensaio comcorpos de prova que não receberam tratamento de limpeza em seu substrato e chapisco. A Figura 8 ilustra a forma de ruptura de cada um dos testemunhos. Os resultados inferiores ao valor mínimo de 0,30 MPa estão destacados na cor vermelha. 
Tabela 1: Resistênciade aderência e forma de ruptura dos corpos de prova que não receberam tratamento de limpeza no substrato e no chapisco

\begin{tabular}{|c|c|c|c|c|c|c|c|}
\hline \multirow{2}{*}{$\begin{array}{l}\text { No DO CORPO } \\
\text { DE PROVA }\end{array}$} & \multirow{2}{*}{$\begin{array}{l}\text { CARGA } \\
\text { (Kgf) }\end{array}$} & \multirow{2}{*}{$\begin{array}{l}\text { TENSÃO Ra } \\
\text { (MPa) }\end{array}$} & \multicolumn{5}{|c|}{ FORMA DE RUPTURA } \\
\hline & & & SUB & SUB/CHAP & CHAP & CHAP/EMB & EMB \\
\hline 1 & 45 & 0,22 & & & & & 100 \\
\hline 2 & 52 & 0,26 & & & & & 100 \\
\hline 3 & 56 & 0,28 & & & & & 100 \\
\hline 5 & 44 & 0,22 & & & & & 100 \\
\hline 6 & 73 & 0,36 & & & & & 100 \\
\hline 9 & 88 & 0,44 & & & & & 100 \\
\hline 10 & 66 & 0,33 & & & & & 100 \\
\hline 11 & 74 & 0,37 & & & & & 100 \\
\hline 12 & 100 & 0,50 & & & 15 & & 85 \\
\hline 13 & 66 & 0,33 & & & & 5 & 95 \\
\hline 14 & 54 & 0,27 & 60 & & 5 & & 35 \\
\hline 15 & 66 & 0,33 & & & & & \\
\hline MÉDIA & 65 & 0,33 & & & & & \\
\hline \multicolumn{2}{|c|}{ DESVIO PADRÃO (Mpa) } & 0,08 & & & & & \\
\hline \multicolumn{2}{|c|}{ COEF. DE VARIAÇÃO (\%) } & 24 & & & & & \\
\hline
\end{tabular}
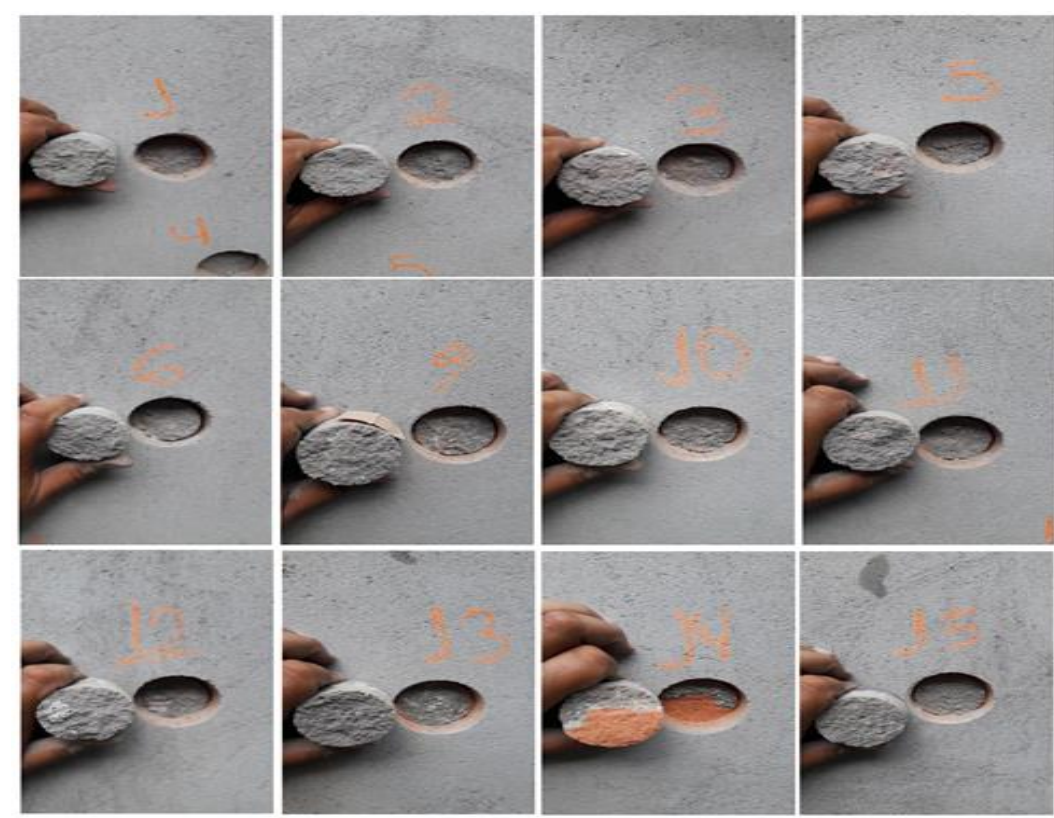

Figura 8: Forma de ruptura dos corpos de prova que não receberam tratamento de limpeza no substrato e no chapisco Fonte: Autor.

\subsection{Ensaio com tratamento do substrato e do chapisco}

A Tabela 2 expressa os valores obtidos a partir do ensaio dos corpos de prova que receberam tratamento de limpeza em seu substrato e chapisco. A Figura 9 ilustra a forma de ruptura de cada um dos testemunhos. 
Tabela 2: Resistência de aderência e forma de ruptura dos corpos de prova que receberam tratamento de limpeza no substrato e no chapisco

\begin{tabular}{|c|c|c|c|c|c|c|c|}
\hline \multirow{2}{*}{$\begin{array}{c}\text { No DO CORPO DE } \\
\text { PROVA }\end{array}$} & \multirow{2}{*}{$\begin{array}{l}\text { CARGA } \\
\text { (Kgf) }\end{array}$} & \multirow{2}{*}{$\begin{array}{l}\text { TENSÃO Ra } \\
\text { (MPa) }\end{array}$} & \multicolumn{5}{|c|}{ FORMA DE RUPTURA } \\
\hline & & & SUB & SUB/CHAP & CHAP & CHAP/EMB & EMB \\
\hline 1 & 92 & 0,46 & & & & 5 & 95 \\
\hline 2 & 61 & 0,30 & & & & & 100 \\
\hline 3 & 75 & 0,37 & & & & & 100 \\
\hline 4 & 86 & 0,43 & & & & & 100 \\
\hline 5 & 63 & 0,31 & & & & & 100 \\
\hline 7 & 69 & 0,34 & & & & & 100 \\
\hline 9 & 65 & 0,32 & & & & & 100 \\
\hline 10 & 105 & 0,52 & 40 & 60 & & & \\
\hline 12 & 72 & 0,36 & & & & & 100 \\
\hline 13 & 125 & 0,62 & & & & & 100 \\
\hline 14 & 106 & 0,53 & & & & & 100 \\
\hline 15 & 83 & 0,41 & & & & & 100 \\
\hline MÉDIA & 84 & 0,42 & & & & & \\
\hline \multicolumn{2}{|c|}{ DESVIO PADRÃO (Mpa) } & 0,10 & & & & & \\
\hline \multicolumn{2}{|c|}{ COEF. DE VARIAÇÃO (\%) } & 24 & & & & & \\
\hline
\end{tabular}

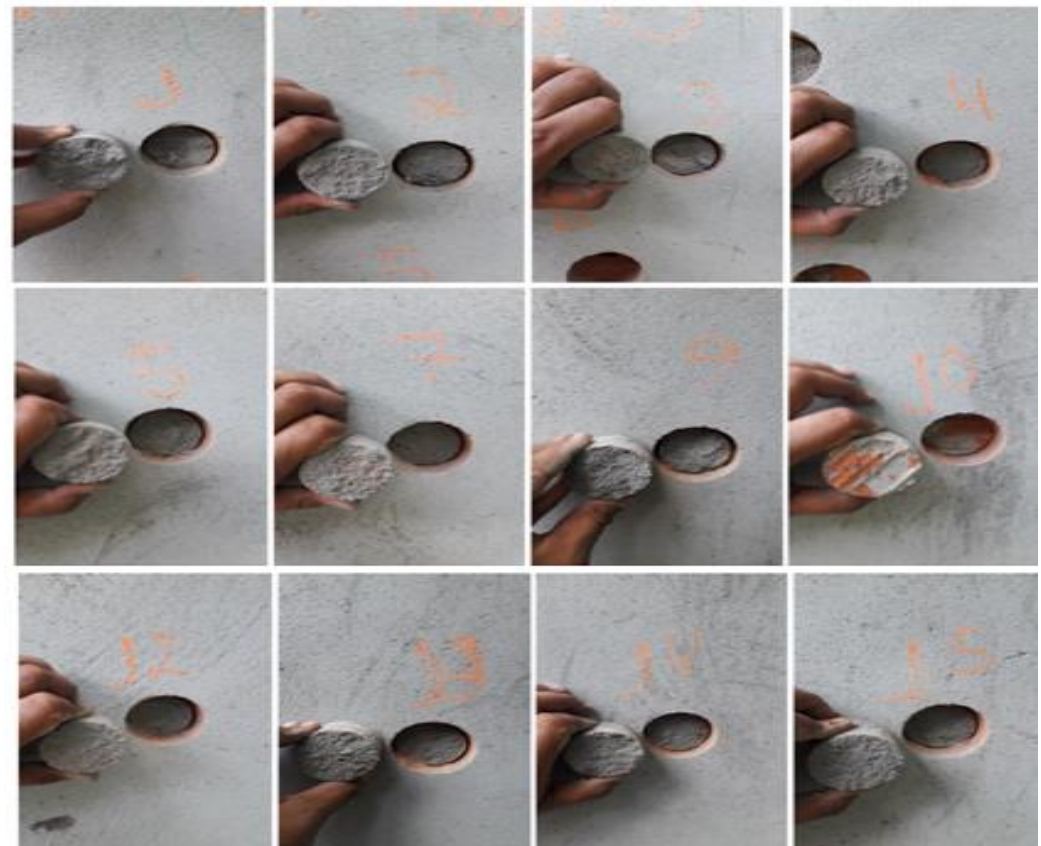

Figura 97:Forma de ruptura dos corpos de prova que receberam tratamento de limpeza no substrato e no chapisco Fonte: Autor.

\section{DISCUSSÕES}

A partir dos valores encontrados na Tabela 1, observa-se que com a ausência do tratamento de limpeza, 7/12 dos valores de tensões obtidas estão maiores ou iguais ao estabelecido pela NBR 13749 [6] $(0,30 \mathrm{MPa})$, ficando em desacordo com a norma que especifica que, para aprovação do pano de ensaio, 2/3 dos valores devem estar acima do limite, ou seja, deveria-se ter 8/12. Emboraum dos resultados eliminados esteja bem próximo ao valor mínimo estipulado de $0,30 \mathrm{MPa}$, e a média obtida, considerando os 12 corpos de prova analisados, seja igual a 0,33 $\mathrm{MPa}$, o ensaio foi reprovado. 
Em contrapartida, ao avaliar o ensaio realizado na região que recebeu tratamento de limpeza, conforme a Tabela 2, os resultados tornaram-se integralmente satisfatórios, com as tensões obtidas dos corpo-de-prova, em sua totalidade, acima de $0,30 \mathrm{MPa}$, e a média alcançando o valor de 0,42 $\mathrm{MPa}$.

Ao analisar apenas a diferença de valoresdas tensões obtidas nas áreas com e sem tratamento, nota-se que aquela que não recebeu tratamento apresentou os menores resultados.

Ao comparar as formas de rompimento de cada situação, é notada a mesma tendência de ruptura,ocorrendo em sua maioria, no trecho do emboço, como demonstram as Figuras 10 e 11.

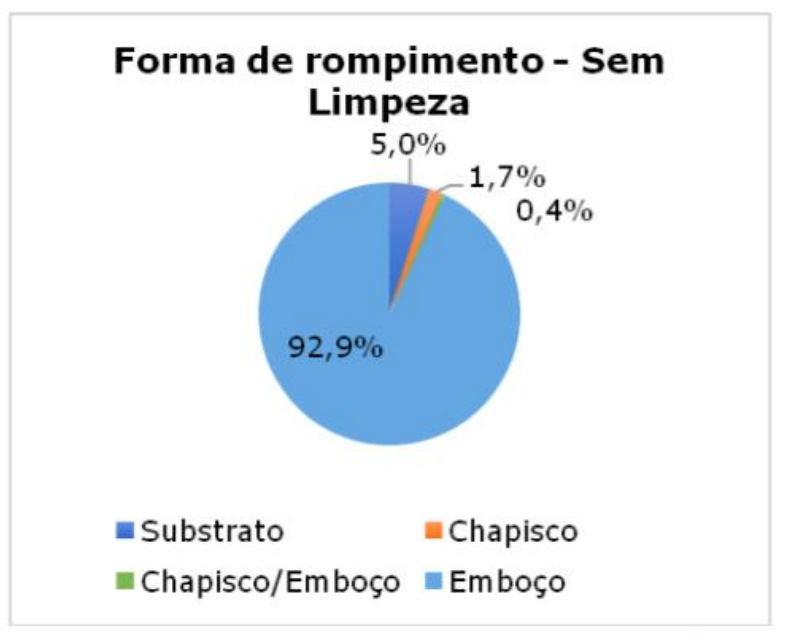

Figura 10: Percentual da forma de rompimento da área sem tratamento.

Fonte: Autor.

Como a única característica que diferenciava as duas áreas ensaiadas era o tratamento de limpeza do substrato e do chapisco, esperava-se que as variações dos resultados fossem ocorrer na forma de rompimento dos corpos de provana área do substrato, substrato/chapisco, chapisco, chapisco/emboço e substrato/emboço. Porém, mais de $91 \%$ dos rompimentos ocorreram no próprio emboço, indicando que as camadas estavam bem aderidas e que os resultados da resistência de aderência são superiores aos encontrados.

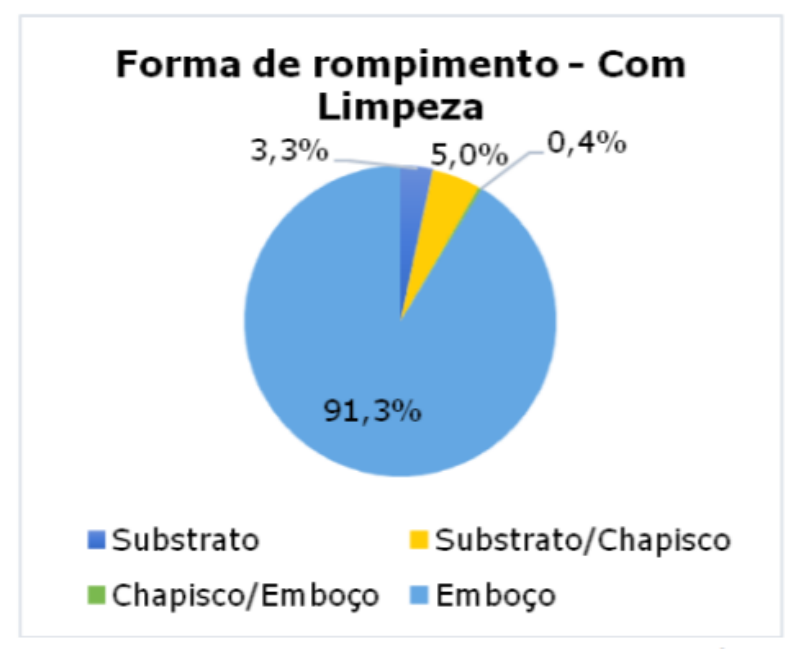

Figura 11: Percentual da forma de rompimento da área com tratamento.

Fonte: Autor.

Conclui-se, para esta pesquisa, que a limpeza não foi o fator fundamental para a variação dos resultados obtidos.

Como os corpos de prova1, 2, 3 e 5, sem tratamento de limpeza, estavamlocalizados no trecho superior do pano de ensaio, a aplicação do emboço foi executada com maior dificuldade pelo funcionário, obtendo os menores resultados de tensão.

Apesar disso, todos os resultados de tensões encontrados no trecho onde houve o tratamento de limpeza foram satisfatórios, garantindo a aprovação do pano e qualidade do produto final.

\section{CONSIDERAÇÕES FINAIS}

Como mais de $91 \%$ dos rompimentos ocorreram no próprio emboço, não foi possível determinar a influência da limpeza do substrato e do chapisco para o aumento da tensão de aderência da argamassa estabilizada, pois os resultados indicaram que as tensões nas interfaces entre as diferentes camadas do revestimento são maiores que as apresentadas, de acordo com a NBR 13528 [9].

Comprovou-se a qualidade do produto final do revestimento realizado conforme a NBR 7200:1998 [5], com a realização do tratamento de limpeza, a partir do ensaio de resistência de aderência à tração, pois todos os valores obtidos deste trecho foram aprovados e satisfatórios. 
Foi notada a necessidade cada vez maior de realização de pesquisas a respeito da argamassa estabilizada. As poucas informações sobre 0 assunto fazem com que os fornecedores sejam escassos e contribui com o desconhecimento por parte dos construtores.

\section{REFERÊNCIAS}

[1] MARTINS NETO, N. A. A. A.; DJANIKIAN, J.G. Aspectos de desempenho da argamassa dosada em central. Boletim Técnico da Escola Politécnica da USP. São Paulo: USP, 1999. (Serie BT/PCC/235). p.23.

[2] LIMA, R. S. A.; OLIVEIRA, R. R. S. Estudo da aderência à tração de argamassa estabilizada para aplicação de revestimento em paredes externas. 2015. Trabalho de Conclusão de Curso (Graduação em Engenharia Civil) - Universidade Anhanguera - Uniderp, Campo Grande, 2015.

[3] SANTOS, H.B.Ensaio de aderência das argamassas de revestimento. Monografia (Curso de especialização em Construção Civil), Escola de Engenharia da Universidade Federal de Minas Gerais, Belo Horizonte, 2008.

[4] ASSOCIAÇÃO BRASILEIRA DE CIMENTO PORTLAND (ABCP). Manual da Argamassa de Revestimento [s.d].

[5] ASSOCIAÇÃO BRASILEIRA DE NORMAS TÉCNICAS. NBR 7200: Execução de revestimento de paredes e tetos de argamassas inorgânicas Procedimento. Rio de Janeiro: ABNT, 1998.

[6] ASSOCIAÇÃO BRASILEIRA DE NORMAS TÉCNICAS. NBR 13749: Revestimento de paredes e tetos de argamassas inorgânicas Especificação. Rio de Janeiro: ABNT, 2013.

[7] MACIOSKI, G. Avaliação do comportamento de argamassas estabilizadas para revestimento. Trabalho final de curso Graduação em Engenharia Civil, Universidade Federal do Paraná, Curitiba - PR, 2014.

[8] MATOS, P. R. Estudo da utilização de argamassa estabilizada em alvenaria estrutural de blocos de concreto. Monografia (Graduação em Engenharia Civil) Universidade Federal de Santa Catarina, Florianópolis - SC, 2013.
[9] ASSOCIAÇÃO BRASILEIRA DE NORMAS TÉCNICAS. NBR 13528: Revestimento de paredes de argamassas inorgânicas Determinação da resistência de aderência à tração. Rio de Janeiro: ABNT, 2010. 